\title{
SASTRA “BACAAN LIAR” HARAPAN MENUJU KEMERDEKAAN
}

\author{
Agus Sulton \\ Lingkar Studi Warung Sastra Jombang \\ Korespondensi: Dusun Payak Santren, Desa Rejoagung RT 03/RW 02 \\ Kec. Ngoro, Kab. Jombang 61473 \\ Pos-el: agus_sul@yahoo.com
}

\begin{abstract}
Abstrak
Penelitian ini berupaya untuk merangkai sumber informasi terkait sastra yang dianggap sebagai «bacaan liar». Pada waktu pemerintahan kolonial, media karya sastra sangat efektif sebagai wadah perjuangan bentuk agitator dan protes kepada pemerintah sekaligus suplemen untuk memahami diri dan nasibnya sehingga harapan untuk keluar dari kolonialisme pemerintahan Belanda lekas terwujud. Pandangan ideologi komunis digunakan pijakan mentransmisikan stabilitas nilai-nilai politik, sosial, dan ekonomi dengan cara vergadering dari gerakan-gerakan radikal revolusioner Bumiputera.
\end{abstract}

Kata kunci: Bacaan liar, ideologi komunis, sastra perjuangan,revolusioner Bumiputera.

\begin{abstract}
This study seeks to assemble relevant literature resources that are considered 'wild readings'. At the time of colonial rule, the literary media was very effective as a vehicle for struggle and protest to the government in addition to serving as a supplement to understand themselves in hopes that Dutch colonialism would soon be over. The communist ideology was used as a framework to transmit stability of political, social, and economic values by way vergadering of radical revolutionary movements of Bumiputera.
\end{abstract}

Keywords: Communist ideology, literary struggle, revolution of Bumiputera, wild reading

\section{PENDAHULUAN}

Karya sastra merupakan cermin dari sebuah realitas kehidupan sosial masyarakat.Sebuah karya sastra yang baik memiliki sifat-sifat yang abadi dengan memuat kebenaran-kebenaran hakiki yang selalu ada selama manusia masih ada (Sumardjo, 1979). Hal ini, suatu karya lahir tidak lepas dari kondisi akan zamannya. Sastra sebagai wadah merekam kondisi sosial, atau kemungkinan sebagai alat politik agar penikmat sastra (pembaca) terpengaruh terhadap pesan yang hendak disampaikan kepada penulis.

Menurut Damono (2002: 1), sastra menampilkan gambaran kehidupan, dan kehidupan itu sendiri adalah suatu kenyataan sosial. Sebab itulah sastra bisa mengandung gagasan yang mungkin dimanfaatkan untuk menumbuhkan sikap sosial tertentu atau bahkan mencetuskan peristiwa sosial tertentu. Ini dapat dilihat dari karyakarya bacaan liar ${ }^{1}$ yang diciptakan oleh nasionalis radikal sebelum zaman kemerdekaan. Selanjutnya Sumarjo (1979: 15) mengungkapkan bahwa kegelisahan masyarakat menjadi kegelisahan para pengarangnya. Begitu pula harapan-harapan, penderitaanpenderitaan, aspirasi mereka menjadi bagian pula dari pribadi pengarangpengarangnya. Inilah sebabnya sifat- 
sifat dan persoalan suatu zaman dapat dibaca dalam karya-karya sastranya. Di dalamnya memuat fenomena-mefomena di masyarakat, salah satunya adalah situasi politik saat karya itu diproduksi. Sehingga bacaan tidak lain sebagai fasilitas komunikasi, propagandis, dan agitator termasuk membentuk sekumpulan organisatoris.

Pada dasarnya, bacaan-bacaan yang dihasilkan oleh para pemimpin pergerakan pada awal abad ke 20 dapat dikatagorikan sebagai bacaan politik. Hampir semua bacaan yang diproduksi oleh para pemimpin pergerakan baik berbentuk novel, puisi, roman, surat perlawanan persdelict dan cerita bersambung, isinya menampilkan kekritisan dan perlawanan terhadap tatakuasa kolonial. Sejarah mencatat, sesungguhnya sastra Indonesia sejak mula sejarahnya merupakan sastra protes (Razif, 2005: 30).

Bacaan menjadi fasilitas komunikasi untuk mendidik kaum kromo. ${ }^{2}$ Propaganda ideologi komunis sebagai jalan untuk melawan ketimpangan kebudayaan. Komunisme dikenalkan di beberapa sekolah, kemudian murid yang berprestasi akandirekomendasikan menjadi pengurus PKI. Selain itu, PKI melakukan propaganda menggunakan media masa dianggapnya sebagai hal ampuh untuk menyadarkan kepada rakyat Hindia Belanda. Dalam posisi seperti ini, PKI merupakan cikal-bakal nasionalisme melawan dominasi kuasa pemerintah Belanda.Kamudian dari situ pada tahun 1924 PKI mendirikan institusi berupa Kommisi Batjaan Dari Hoofdbestuur PKI.Komisi ini menerbitkan dan menyebarluaskan tulisan-tulisan serta terjemahanterjemahan "literatuur socialisme" istilah ini dipahami oleh orang-orang pergerakan sebagai bacaan-bacaan guna menentang terbitan dan penyebarluasan bacaan-bacaan kaum modal. ${ }^{3}$

Memang pada awal-awal tahun 1920-an atau setelah Sneevliet datang ke Hindia Belanda banyak mengubah kondisi politik rakyat pribumi. Serikatserikat buruh, perhimpunan, organisasi tumbuh begitu pesat dengan ideologi komunis yang diusung. Menurut Yuliati (2000:1) tujuan dari organisasiorganisasi tersebut, tidak lain adalah mencari bentuk-bentuk persatuan untuk mewujudkan langkah-langkah demi kemajuan kehidupan bangsa.

Pertumbuhan organisasi serikat buruh ini diikuti pula oleh surat kabar dari kelompok organisasi, dan sastra sebagai alat untuk menyampaikan pesan (propaganda) politik tertentu, mulai dari syair, cerpen, roman, dan novel seperti Rasa Mardika karya Soemantri (novel 1924), syair Sama Rasa dan Sama Rata karya Mas Marco (Sinar Djawa, 10 April 1918), syair Bajak Laut karya Mas Marco (Sinar Hindia, 23 Desember 1918), syair Kehilangan Kecintaan Kita karya Soetjipto (Hidoep, 1 Maret 1925), Hikajat Kadiroen karya Semaoen (novel 1920), Semarang Hitam karya Mas Marco (cerpen 1924), Gadis Desa karya W.R Soepratman (roman 1920), dan sebagainya.

Bacaan-bacaan dari kaum pergerakan sangat membahayakan dan mengancam keberadaan pemerintah. Rinkes (direktur Balai Pustaka) menyatakan harus dijauhkan bacaan yang dapat merusakkan kekuasaan pemerintah dan ketentraman negeri dan diperluas bacaan-bacaan yang diproduksi oleh Balai Pustaka. Hal-hal inilah yang signifikan mendasari, kenapa karya pribumi berhaluan kiri perlu untuk diteliti dan diangkat ke permukaan lagi, setidaknya menemukan gambaran awal aktivitas-aktivitas kaum pergerakan untuk merealisasikan kehidupan yang lepas dari kolonialisme. 
Dengan kata lain menawarkan solusi kontradiksi untuk resolusi sejarah sastra Indonesia yang selama ini tonggak awalnya dimulai dengan produk-produk Balai Pustaka. Berdasarkan penilaian Toer (2003: 119-120) bahwa sastra tahun belasan telah mulai dengan tradisi memenangkan objektivitas, dapat dibuktikan dari garapannya tentang realitas sosial, tentang aspirasi nasional untuk merdeka. Sudah sejak ini nampak dan diucapkannya pergulatan bangsa Indonesia untuk menguasai dirinya sendiri, buminya sendiri. Dan inilah realitas yang objektif.

Dalam awal abad ke-20 nuansa pergerakan di Hindia Belanda mengalami perkembangan yang sangat pesat.Organisasi-organisasi dan serikat buruh membentuk suatu kesatuan untuk melawan kolonialisme dan imperialisme Belanda.Gerakan komunis diterjemahkan sebagai langkah untuk ingin merdeka, terlepas dari kesengsaraan secara menyeluruh.Orgaan adalah alat yang ampuh untuk mempengaruhi masa, menciptakan kesadaran kepada kaum kromo.Selain itu, bentuk-bentuk openbare vergadering, mewujudkan volksraad, pemogokan, nyanyian dan karya sastra.

Dalam era perkembangannya, Semarang merupakan salah satu tempat perkembangan kehidupan politik dan jurnalistik yang penting. Berbagai organisasi yang berkembang di kota ini mendorong pertumbuhan dan perkembangan persuratkabaran. Sarekat Islam Semarang mempunyai surat kabar Sinar Djawa (1914-1918), dalam tahun 1918 berganti nama Sinar Hindia (19181924); Perhimpunan Pegawai Negeri Sekolah Rendah, Tjahjo Pramono menerbitkan Soeara Satelian (1919); Vereeniging voor Spoor en Tramweg Personeel (VSTP) memiliki SI Tetap (1919-1925). Kemudian Persatoean Hindia (1919-1921) menjadi media pergerakan National Indesche Partij, dan Api menyuarakan kepentingan PKI. $^{4}$

Pada masa yang sama, di Semarang berdiri delapan rumah cetak, di antaranya firma Benjamin 'Co, firma Bisschop 'Co, firma Masman 'Stroink, N.V. Dagblad "De Locomotief", de N.V. Hap Sing Kongsie, dan de firma Misset 'Co (Razif, 2005: 31). Ada juga, Druk-kerij VSTP ${ }^{5}$ sebuah percetakan dan penerbitan milik organisasi kereta api dan traam. Beberapa dari firma tersebut menjadi corong untuk menerbitkan karya-karya berhaluan kiri, dianggap sangat membahayakan pemerintah Hindia Belanda waktu itu.Bacaan-bacaan dari kaum pergerakan menyuarakan perlawanan, mendidik rakyat kromo,dan protes kepada pemerintah Belanda.

\section{MUNCULNYA BACAAN LIAR}

Istilah "bacaan liar" sendiri pertama kali diucapkan oleh Rinkes ${ }^{6}$ pada tahun 1914 untuk tulisan-tulisan kaum pergerakan, baik berupa novel, roman, puisi, artikel, maupun buku pemikiran. Pada waktu itu pemerintah merasa khawatir terhadap bacaan berupa surat kabar dan karya sastra. Pemaparan Razif (2005: 37) menjelaskan kalau pemerintah kolonial mulai gencar mengatasi derasnya bacaan yang mulai menyinggung kekuasaan kolonial, baik yang dihasilkan rakyat pribumi atau Tionghoa peranakan. Sebagaimana diungkapkan:

The only publication that dominated all those, with Darma Kanda as the exception, and something more than a local newspaper with personal slanging match (met personlijke scheld partijen) was Medan Prijaji....wich besides sharing the character with other showed itself as more energetic, gifted, cunning and more poisonous and which 
declared Java as its territory of action (terrein van actie).

In beginning it was published as a weekly an after being develop, within 2 years it had been converted into a daily, constantly loved, and according to some it has 2000 subscribes. In itself a European newspapers in the indies that is not a bad figure, which is even more so for a Malay newspaper.....

In the weekly and later daily newspaper...The goverment and goverment regulations were ridiculed and at same time those half-baked groups (de kringen van half-ontwikkelen) were captivated and influenced by (its) deception, by pushing (them) to improve their lot and the like.

Surat kabar harian maupun mingguan isinya seringkali provokatif, menyerang pemerintah kolonial, mengejek aturan-aturan pemerintah dan menyerang pejabat pemerintah, maka bacaan-bacaan tersebut dianggap telah melanggar kekuasaan kolonial dan mengganggu ketertiban. Lebih jauh pernyataan Rinkes ini merupakan hasil perdebatan dengan Mas Marco Kartodikromo pada tahun 1914 tentang hasil-hasil kerja Mindere Welvaart Commissie, yang dianggap Mas Marco sebagai usaha mempertahankan mitos politik etis. $^{7}$

Dari permulaan bisa diidentifikasi, bahwa bacaan liar atau karya sastra yang disebut liar salah satunya bermaksud untuk mendidik kaum kromo. Razif (2005: 30) kembali mempertegas, demi menghela rintangan-rintangan bagi pergerakan diperlukan bacaan-bacaan politik, agar kaum kromo mengetahui, memahami, dan menyadari politik kekuasaan kolonial.Bacaan-bacaan yang dihasilkan oleh para pemimpin pergerakan di atas dapat dikatagorikan sebagai "bacaan politik".
Bagi kaum pergerakan, bacaan merupakan alat penyampai pesan dari orang-orang atau organisasi-organisasi pergerakan kepada kaum kromo. Oleh spektrum revolusioner dan radikal dari kaum pergerakan, bacaan diisi pesan tentang jaman telah perubah dan penindasan kekuasaan kolonialisme. Pada dasarnya, tujuan dari penerbitan didirikan adalah agar pesan-pesan tersebut dapat mengajak rakyat kaum kromo melawan penjajah, menyebarkan dan mengajarkan sosialisme, menghapus hubungan-hubungan sosial lama yang telah usang yang tetap dipertahankan oleh kekuasaan kolonial seperti aturan sembah jongkok ketika pertemu atasan dengan pejabat atau pembesar kolonial, melawan dominasi penerbitan barang cetakan yang diproduksi oleh Balai Pustaka. ${ }^{8}$

Pernyataan seperti itu pernah disinggung oleh Moeso dalam surat kabar Proletar, 23 Juli 1925 berjudul "Boekoe-boekoe sendiri, pikiran-pikiran sendiri, moral sendiri"

Kaoem kapital sekarang
menerbitken matjam-matjam
boekoe jang tidak terhingga
banjaknja. Itoe semoea maksoednja
tidak lain jaitoe oentoek
menyesatken dan membingungken
kaoem boeroeh, soepaja ini tidak
bisa melawan keras-kerasan sebagai
mestinja.
Apabila sekolahan-sekolahan rakjat
dalem tempo-tempo terachir
mendapet rintangan begitoe banjak,
itulah disebabken karena ditakutilah
jang anak-anak itoe nanti terlepas
dari boeah-boeah pikiran jang
merugiken kepada kaoem boeroeh
itoe.
Karena itoelah kaoem boeroeh dan
kaoem tani jang tertindas di sini
tidak seharoesnja menbatja boekoe-
boekoe jang diterbitken oleh pihak
sana, karena boekoe-boekoe ini

Kaoem kapital sekarang menerbitken matjam-matjam boekoe jang tidak terhingga banjaknja. Itoe semoea maksoednja tidak lain jaitoe oentoek menyesatken dan membingungken kaoem boeroeh, soepaja ini tidak bisa melawan keras-kerasan sebagai mestinja

Apabila sekolahan-sekolahan rakjat terachir njak, jang anak-anak itoe nanti terlepas dari boeah-boeah pikiran jang merugiken kepada kaoem boeroeh itoe.

Karena itoelah kaoem boeroeh dan kaoem tani jang tertindas di sini tidak seharoesnja menbatja boekoesana, karena boekoe-boekoe ini 
tjuma oentoek menguatken tindasan sadja, lain tidak!

Oentoek mempertjepat datengnja kemerdekaan kita, haroeslah sekalian saoedara membatja boekoeboekoe sendiri, jang ditoelis oleh orang-orang dari lasnja sendiri.

Tulisan Moeso di atas berusaha menyadarkan kepada pembaca, khususnya kaum kromo terhadap bahaya kaum kapitalis.Dengan membaca karyakarya yang berpihak kepada kaum buruh maka harapan untuk segera lepas dari kolonialisme segera terwujud, dan menjadi negara merdeka. Selain dari Moeso, Mas Marco Kartodikromo dalam Sinar Djawa, 1 April 1918 "Djangan takoet" menyarankan kepada rakyat Hindia Belanda (pembaca) untuk membaca surat kabar yang memihak kaum orang, bukan memihak kepada kaum uang.

Kita memberi ingat kepada saudara-saudara, djanganlah soeka membatja sembarang soerat kabar, pilihlah soerat kabar jang betoelbetoel memihak kepada kaoem orang, tetapi jangn tidak memihak kaoem oeang. Sebab kalau tidak begitoe, soedah boleh ditentoeken, achirnja kita orang Hindia tentoe akan terdjeroemoes di dalam lobang kesengsara'an jang amat hina sekali.

Bacaan ini setidaknya memberikan kontribusi kecerdasan dan sikap keberanian rakyat pribumi untuk membangkitkan politik gerakan masa.

Puncak terbitan karya sastra "bacaan liar" antara tahun 19181926.Tahun 1918 menjadi pertanda mulai mengalami perkembangan bacaan yang mengagitasi dan propaganda kepada rakyat, di samping itu pecahnya revolusi Bolsjevik di Rusia memberikan dampak politik pergerakan di Hindia Belanda.Para kaum pergerakan aktivitasnya semakin radikal dengan menyuarakan kritik pada pemerintah kolonial. Ini ditandai dengan tulisan syair Mas Marco Kartodikromo "Sama Rata dan Sama Rasa" yang dimuat Sinar Djawa, 10 April 1918 dan dengan waktu yang hampir bersamaan saat peralihan nama menjadi Sinar Hindia, tulisan cerita bersambung Mas Marco Kartodikromo berjudul "Student Hidjo" dimuat di surat kabar yang sama tahun 1918. Menurut Shiraishi (2005: 119) Mas Marco Kartodikromo berkampanye menentang milisi Bumiputera dan indie weerbar, sambil menuntut persamaan antara Bumiputera dan Eropa. Kurang dari seminggu ia terkena tahanan preventif lagi, lalu menjalani hukuman kurang selama satu tahun.

Sementara itu, tahun 1926 produk "bacaan liar" mengalami kemunduran setelah pemberontakan PKI itu pecah tahun1926-1927. Cahyono (2003: 129) menyimpulkan bahwa tahun 1926 pelemahan besarbesaran yang terjadi pada gerakan buruh. 4.500 orang buruh dan aktivis kiri dijebloskan ke penjara, empat hukuman mati, 1.300 dibuang ke Boven Digoel. Berdasarkan data Petrus Blumberger, tidak menyebutkan 4.500 buruh dan aktivis kiri, namun akibat dari pemberontakan itu kira-kira 1.300 orang yang ditangkap dan dimasukkan ke dalam berbagai penjara di Nusantara yang luas itu akibat kegiatan komunis mereka. ${ }^{10}$ Menurut Pringgodigdo (1950: 32) dan Salim (1977: 37) pada Maret 1928 , ada 823 orang yang dikirim ke Digul. 15 orang perempuan dan 10 orang Tionghoa, diantaranya 629 orang Djawa, 77 dari Sumatera dan 33 dari Maluku; diantaranya 9 berumur kurang dari 20 tahun, 442 berumur 20-29 tahun, 81 berumur 40-49 tahun, diantaranya 383 pegawai rendah, 79 petani, 361 guru, supir dan pegawai kecil. Shiraishi (2001: 10) mencatan pada Februari 1928 orang di Digul ada sekitar 1.139, terdiri dari 666 internir dan 473 
keluarga. W.P. Hillen bulan April 1930 penghuni Digul ada sekitar 2.000 orang, termasuk 1.308 interniran.

Pembuangan para aktivis serikat buruh dan kaum komunis pergerakan buruh di Hindia belanda semakin melemah.Pemberontakan PKI 1926 dinilai Cahyono (2003: 129) menunjukkan kuatnya keinginan kaum Bumiputera untuk merdeka dari Negara Kolonial Hindia Belanda.Semangat kaum pergerakan komunisme itu melakukan macam-macam strategi sebagai rasa nasionalisme, salah satunya media karya sastra.

\section{BACAAN LIAR DAN SASTRA PROTES}

Karya sastra yang dicap "bacaan liar" sehingga dianggap berbahaya yang menyuarakan protes atau propaganda. Karya-karya model seperti ini jarang diberbincangkan dalam sejarah sastra Indonesia, diantaranya;

1) Karya Mas

Kartodikromo $^{11}$ Kartodikromo

adalah seorang jurnalis surat

kabar Medan Prijaji, Doenia

Bergerak, dan majalah

Sarotomo, Pantjaran Warta.

Lahir di Cepu, 1890 kamudian meninggal di Bovel Digoel tahun 18 Maret 1932. Kegiatan Marco banyak dicurahkan dalam organisasi pergerakan. Pada tahun 1915 Mas Marco dipenjara tujuh bulan lantaran persdelict atas empat surat pembaca di surat kabar Doenia Bergerak, kemudian tidak berselang lama tahun 1917 gara-gara syair "Sama Rata dan Samara Rasa" dijebloskan ke penjara lagi selama satu tahun. Pada tahun Juni 1927 Mas Marco dibuang ke Bovel Digoel bersama 64 orang lainnya karena terlibat gerakan komunisme. Karyakarya Mas Marco, yaitu:

- "Sair Rempah-rempah" terbit di Druk N.V. Sinar Djawa Semarang tahun 1918

- Syair "Indie Weerbaar" terbitSinar Hindia 2 September 1918

- Novel "Student Hidjo" terbit di Semarang 26 Maret 1919

- Novel "Matahariah" terbit di Semarang 1918

- Syair "Sama Rata dan Sama Rasa" Sinar Djawa, 10 April 1918 dan Pabtjaran Warta, 13 Februari 1917

- Syair "Bajak Laut" Sinar Hindia, 23 Desember 1918

- Novel "Mata Gelap: Tjerita jang Soenggoeh Kedjadian di Tanah Djawa" terdiri dari 3 jilid, setiap jilid harganya f. 0,15,- diterbitkan Insulinde Bandung tahun1914.

- Cerita pendek "Semarang Hitam" dimuat Sinar Hindia dan Api, 30 September - 6 Oktober 1924

\section{2) Semaoen}

Semaoen lahir 1899 di Curah Malang, Sumobito, Jombang dan meninggal di Bandung 1971.Karir pertamanya dimulai memasuki SI Surabaya, dia masuk juga di ISDV afdeeling Surabaya dan VSTP afdeeling Surabaya.Pada tahun 1916 Semaoen dipindahkan VSTP Semarang sambil bekerja sebagai redaktur Si Tetap, Sinar Hindia.Tahun 1920 Semaoen menjadi ketua PKI, tiga tahun kemudian dia diasingkan ke Belanda 18 Agustus 1923. ${ }^{12}$ Pada masa di Hindia Belanda banyak menulis artikel-artikel perlawanan kepada pemerintah, 
wacana kritis, dan melancarkan pemogokan. Karya-karya Semaoen bentuk buku adalah "Penoentoen Kaoem Boeroeh" terbit di Semarang Mei 1920, "Persdelict Semaoen" terbitan SI Semarang tahun 1919, sedangkan tulisan yang berupa karya sastra, yakni:

- Novel Hikayat Kadiroan terbit kantor PKI Semarang tahun 1920

- "Hindia Merdika dan Selamat" puisi ini ditulis Semaoen pada 24 Juli 1919

\section{3) Soemantri}

Menurut Sumarjo (2004), Teeuw (1980), Damono (1999), dan Wasono (2007) menyebut Rasa Mardika adalah karya Mas Marco Kartodikromo. Takashi Shiraishi (2005) dalam buku "Zaman Bergerak" menyinggung novel Rasa Merdika sebagai hasil karya dari Soemantri. Anderson (1983) menyebut kalau Soemantri adalah teman pergerakan Mas Marco Kartodikromo di Semarang. Pendapat yang sama juga dikatakan oleh Razif (2005) bahwa Rasa Merdika ditulis oleh Mas Marco Kartodikromo dengan mempertimbangkan dua alasan; (1) Mas Marco pada tahun 1924 sedang sibuk menulis "Babad Tanah Djawa," satu naskah yang memerlukan konsentrasi dan waktu yang banyak, (2) Soemantri adalah sebagai pemimpin redaktur $S i$ Tetap, organ VSTP.

Berdasarkan informasi yang terdapat dalam surat kabar Sinar Hindia, 31 Mei 1923 ada beberapa tokoh VSTP yang ditangkap lantaran terkena pasal
161 bis ${ }^{13}$ pada tanggal 14 Mei 1923 atau sebelumnya melakukan pemogokan besarbesaran di Semarang, seperti Semaoen, Soemantri, Soendoro, Abdoelrachman, Soedibio, $\mathrm{H}$. Abdoeladjis, Wirjosoetikno, dan Ngadino. Pemogokan itu tidak hanya dari VSTP, tapi meluas mempengruhi pada pekerja bengkel, pasar rakyat, dan sopir taksi.

Tidak ada data yang menjelaskan secara lengkap mengenai keberadaan Soemantri, sebab pada bulan juni 1927 Mas Marco Kartodikromo diasingkan ke pembuangan Bovel Digoel dengan 64 tahanan. Kemungkinan Soemantri diasingkan ke Boven Digoel bersama dengan Mas Marco Kartodikromo. Dalam tulisan Mas Marco lain kesempatan mengatakan, bahwa selama di Boven Digoel Soemantri menjadi sekertaris dari anggota comite van actie (komite aksi) berdasarkan rapat majelis kampung. Selama comite van actie berdiri, berulang kali mengadakan kongres salah satunya untuk membentuk persatuan seluruh onderafdeeling (kawedanan) Boven Digoel, yang kemudian dinamakan Centrale Raad Digoel (Dewan Pusat Digoel) pada 24-27 Januari 1928. Dalam pemilihan ketua saat kongres C.R.D berlangsung, Aliarcham mendapatkan suara terbanyak, yaitu 515 suara, disusul Boedisoetjitro dengan 462 suara, dan Soemantri dengan 438 suara. Pada tanggal 2 Februari 1928 C.R.D mengadakan 
vergadering yang pertama dan memilih voorzitter, yaitu Sardjono.Juga membentuk Ехеси, comite di luar C.R.D, dari 11 orang terpilih Soemantri sebagai voorzitter. ${ }^{14}$

Berdasarkan pendapat Salim (1977: 341) dan Shiraishi (2001: 35), bahwa pada Mei tahun 1928, kontrolir Monsjou memutuskan untuk menghancurkan C.R.D, dan pada akir tahun iti pula kaum interniran (kaum pengasingan Bovel Digoel) dipindahkan ke kamp Gunung Arang, di sebelah selatan Tanah Merah. Dalam kelompok itu termasuk Aliarcham, Sardjono, Mohammad Sanoesi, Soenario, Soemantri, Dachlan, Najoan dan beberapa pengikutnya.

Awalnya kaum pergerakan yang diasingkan ke Boven Digoel masih mengerti mana kawan dan mana lawan, semangat membentuk organisasi propaganda.Para anggota komunis masih bersatu.Seiring berjalannya waktu merekamereka dari anggota komunis tidak tahan atas siksaan, ancaman, dan tekanan.Dulu di Jawa yang dulunya kawan pergerakan, akhirnya tunduk pada kolonial Belanda.Posisi kawan berubah menjadi lawan.Keimanan mereka tunduk, terbentur karena sistem pemerintah di Boven Digoel, dengan maksud berubah haluan dari pergerakan menjadi pro kolonial agar bisa segera pulang ke Jawa. Sumber informasi tulisan Mas Marco Kartodikromo di koranPewarta Deli 24 November 1931 (Koran Pewarta Deli dari 10 Oktober - 9
Desember 1931, suntingan Koesalah Soebagyo Toer, 2002) mengatakan orang-orang pergerakan komunis yang masih tahan iman terhadap siksaan di Bovel Digoel adalah Dahlan, Najoan, dan Mas Marco Kartodikromo.

Keadaan Soemantri tidak lagi sekawan dengan Marco, dia berubah pemikiran yang tunduk pada kolonial.Soemantri semakin rusak mental dan psikis. Catatan Marco pada 1 Desember 1931 menyatakan Soemantri dari Semarang meninggal di hospital Ambon lantaran sakit raja singa. Pergaulan di Bovel Digoel sangat bebas, orang bisa tukar pasangan atau suami menjual istrinya karena minimnya orang perempuan.Penyakit raja singa bisa jadi akibat dari seks bebas. Namun orang pengasingan yang menderita sakit parah, dalam artian rumah sakit di Bovel Digoel tidak mampu maka pasien itu dirujuk ke Ambon atau Makasar, seperti pada kasusnya Soenarjo, dia di bawa ke Makasar karena menderita zwarte-water-koorts (malaria hitam) setelah bekerja di hutan. Karya Soementri yang diketahui untuk sementara hanya berupa karya sastra, yaitu:

- Novel Rasa Merdika (Hikajat: Soedjanmo) diterbitkan Druk-kerij VSTP Semarang tahun 1924.

- Novel Rahasia Terboeka diterbitkan Druk-kerij VSTP Semarang tahun 1925

Sebenarnya masih banyak para penulis dari "bacaan liar" namun secara sosiologi pengarang, peneliti belum menemukan beberapa biografi secara detail, seperti halnya Soetjipto menulis puisi “Kehilangan Kecintaan Kita: Rosa 
Luxemburg dan Karl Liebnecht" dimuat di surat kabar Hidoep, 1 Maret 1925, roman Gadis Desa karya W.R Soepratman tahun 1920, Hadji Moekti menulis roman Hikayat Siti Mariah tahun 1910.

Pada tahun-tahun sebelumnya, orang pribumi yaitu R.M. Tirtoadhisoerjo tergolong penulis yang banyak menghasilkan karya sastra, misalnya; Pertjintaan 101 Tjerita jang soenggoe terjadi di Tanah Priangan terbit 1906, Tjerita Njai Ratna terbit tahun 1909, Membeli Bini Orang dan Busono terbit bersamaan tahun $1912 .^{15}$ Sebagaimana dikatakan Toer (2003: 118), karya-karya R.M. Tirtoadhisoerjo kaya akan materi sosial dan kukuhnya ia menguasainya. Untuk pertama sejarah sastra Indonesia dibekali dengan suatu bobot yang buat kegatraan sastra boleh dinilai dan ditimbang sebagai objektif karena persoalannya adalah persoalan golongan yang menguasai masyarakat pada waktu itu, golongan yang jadi acuan kehidupan semua orang.

Produksi bacaan dari orang pergerakan setelah R.M. Tirtoadhisoerjo menghimpun dalam kelompok "literatuur sosialisme."Hasil karya yang diciptakan memang tidak sebanyak dengan produksi Balai Pustaka. Menurut Soekindar (1921), produksi bacaan "literatuur sosialisme" pada tahun 1917 ada disiarkan 8 kitab, tahun 1918 ada 15 kitab, tahun 1919 ada 26 kitab, tahun 1920 ada 32 kitab, dan tahun 1921 hingga tiga kwartal dalam tahun 1925 ada 70 kitab. ${ }^{16}$ Macammacam kitab (buku) yang diproduksi tersebut ada berupa syair, novel, bacaan pemikiran, dan sejarah.

Harga buku yang diproduksi dan edarkan tidak terlalu mahal.Dalam surat kabar Mawa, 3 Juli 1925 yang dikutip oleh Razif (2005), Mas Marco Kartodikromo memasang sebuah iklan tentang harga-harga buku untuk kaum pergerakan, bahwa harga Rasa Mardika (Hikajat Soedjanmo) adalah f.0,95, Manifest Kommunist f.0,65, Kommunisme I (apakah maoeja kaoem kommunist?) f.0,30, Kommunisme II (P.K.I dan kaoem boeroeh) f.0,35, Pemogokan Besar di Shanghai f.0,30, Student Hidjo f.1,60, Sjair Internationale f. 0,15. Untuk harga, seperti Hikayat Kadiroan dijual dengan harga f. 0,25,-, majalah Pandji Poestaka dijual f. 0,20,-.

Dijualnya buku-buku dengan harga murah di atas agar rakyat kromo mampu membeli. Pada sisi yang lain, kaum pergerakan mempunyai misi mempengaruhi masyarakat umum. Sehingga bahasa pengungkapan teks terbilang relatif merakyat, atau bisa disebut bahasa pasar. Bahasa dalam buku tidak jauh beda dengan bahasa yang dipergunakan oleh rakyat miskin dalam percakapan sehari-hari dalam pergaulan. Tidak mengikuti konfensi bahasa baku seperti halnya karya-karya yang diterbitkan Balai Pustaka.

Produksi

"litteratuur socialistisch" oleh para penulisnya ditujukan untuk pendidikan rakyat jajahan, agar berpikir bagaimana jalan pergerakan tidak jauh ke arah yang anarkis, dan sekaligus mengajak kaum terpelajar Bumiputera untuk turut memikirkan pergerakan.Sudah sangat jelas pernyataan bacaan-bacaan yang dikeluarkan oleh pemerintah mengacu pada bacaan Balai Pustaka.Ini merupakan propaganda anti bacaan yang diproduksi oleh Balai Pustaka, yang berusaha mentransmisi nilai-nilai politik dan sosial dengan harapan dapat mempengaruhi pemikiran, emosi dan sekaligus tingkah laku rakyat Bumiputera. Aliarcham dan para pemimpin pergerakan yang menulis di bawah naungan Kommisi Batjaan Hoofdbeestuur PKI menyadari bahwa kelas borjuis senantiasa menciptakan kebudayaannya sendiri dan di Hindia melalui produk-produk Balai Pustaka 
berusaha menghegomoni rakyat Bumiputera.Untuk menentang bacaan kelas borjuis, kaum intelektual proletar harus merekontruksi kebudayaan proletariat. Aliarcham juga menyatakan bahwa menciptakan kebudayaan yang baru bukanlah hal yang mudah, karena akan selalu mendapat halangan dari kebudayaan borjuis yang telah berakar berabad-abad di kepala proletar sekalipun. Tetapi kultur baru ini harus dicapai. $^{17}$

Dari sini terlihat bahwa produk dan penyebaran bacaan merupakan hal pokok dari pergerakan, sebagai pengikat dan roda mesin sosial demokrasi. Disamping itu, kaum pergerakan sering menggunakan istilah "Hikajat".Kata ini memberi pemahaman kepada pendukungnya tentang sejarah kekuasaan masyarakat kolonial. Hikajat merupakan message kepada para pembaca untuk memahami tahap-tahap perkembangan sejarah hubunganhubungan produksi dan kekuasaan kolonial Hindia Belanda.Sebagaimana dikatakan Semaoen bahwa Hindia Belanda adalah negeri di mana "Hikajatnja drajat-drajat jang berkoeasa dalam pemerintahan negri didalam pripenghidoepan bersama-sama".Pada zaman purbakala tingkat pengetahuan masyarakat terbatas pada kepala atau pemimpin yang mempunyai kekuasaan. Pemimpin ini begitu berkuasa di atas golongan-golongan masyarakat lainnya, sehingga apa yang dikehendaki harus dituruti oleh yang di bawah. ${ }^{18}$

Dalam prespektif ini, rakyat bawah tidak lain sebagai alat produksi dan mudah untuk diintimidasi. Gambaran seperti ini sangat mudah kita temukan dalam karya-karya sastra liar tahun 1920-an, halnya novel Rasa Merdika karya Soemantri terlihat saat dialong keduanya; Soedjanmo dan Kromotjiloko menyebutkan bahwa diri Kromotjiloko adalah orang miskin dari desa yang sawahnya disewa oleh para pemodal.

Saja adalah seorang jang meskin. Di desa kediaman saja, desa Lapangmanis, saja ada mempoenjai sawah $1 \frac{1}{2}$ bouw tinggalan dari saja poenja orang toea jang soedah meninggal doenia. Saja tanami padi dapetlah menghatsilken kira-kira 30 datjin jang kalau saja djoeal bisa lakoe koerang lebih 120 roepijah (Soemantri, 1924: 40).

Gambaran tersebut memperhatikan secara jelas kalau rakyat yang sebelumnya hidup melimpah; kebutuhan keluarganya tercukupi dengan hasil tanaman padi. Akhirnya berubah drastis akibat kaum kapitalis merebut sawahsawah rakyat di desa. Hal ini menjadikan rakyat pergi menjadi kuli ke kota, seperti yang terjadi pada diri Kromotjiloko.
"Ja....tetapi.......serenta di dekatnja saja poenja desa ada didiriken seboeah paberik goela jang baroe ada dalem tempo setahoen jang belakangan ini, sekarang saja terpaksa pergi dari saja poenja desa dengen meninggalken saja poenja anak isteri, lantaran...........saja poenja sawah disewa oleh paberik goela itoe, boeat ditanami teboe." (Soemantri, 1924: 40).

Kelas kapitalis dalam novel Rasa Merdika ditandai dengan berdirinya pabrik-pabrik gula yang berkembang pada saat itu. Apa yang terjadi pada awal abad ke 20 adalah sebuah kesengsaraan monopoli yang terus terjadi pada rakyat-rakyat di desa. Memang pada saat di mana karya itu diciptakan, persoalan kemiskinan menjadi sorotan utama kaum pergerakan pribumi di Hindia Belanda.

Seperti apa yang dilakukan Soedjanmo melihat kondisi desa naungan ayahnya. Rakyatnya sangat miskin, namun Soedjanmo belum 
mampu menolong karena masih belum banyak mengerti penyebab dari kemiskinan itu. Dia merasa keberatan apabila disuruh magang pegawai negeri oleh Bey Soemo.

Kami kira, meskipoen akoe bekerdja setengah mati dalem pekerdjaankoe, toh akoe aken ta'dapet membikin apa-apa bagi menolong kromo keloear kesengsaraan jang soedah banjak kami selidiki di desa-desanja bapa ini (Soemantri, 1924: 9).

Memang menjadi suatu penanganan khusus untuk mengamati kondisi sosial dan ekonomi rakyat Hindia Belanda, tertama lingkungan Soedjanmo berada. Sebab hal yang nyata adalah lahan-lahan terhampar dengan luas tetapi tidak diimbangi dengan nasib rakyat sekitarnya. Persoalan tersebut membuat hati Soedjanmo bingung, tidak mampu bekerja apa-apa karena memikirkan pergaulan hidup umum.

Dalam tulisan Mas Marco Kartodikromo di Sinar Djawa, 26 Maret 1918 berpendapat betapa sengsaranya bangsa kita orang desa yang tanahnya sama disewa pabrik.....caranya pabrikgula hendak menyewa sawah orang-orang desa itu yang sudah kejadian lantaran dari politie desa: Lurah, Carik enz, enz, jadi pabrik tidak usah rewel-rewel masuk keluar di rumah-rumah orang desa yang sawahnya hendak disewa pabrik. Banyak orang-orang desa bilangan pabrik Cepiring dan Gemuh afdeling Kendal, Semarang, bahwa mereka itu merasa terlalu menyesal sekali,karena sawahnya disewa oleh pabrik, sebab uang sewaan tanahnya dari pabrik itu lebih sedikit dari pada hasil kalau itu tanahnya dikerjakan sendiri.

Sikap kaum kapital ini menyengsarakan rakyat Hindia Belanda. Para petani itu kini tidak lebih daripada budak-budak belian. Areal perkebunan yang semakin lama semakin meluas ini, mengakibatkan semakin berkurangnya areal persawahan. Dengan mudah dapat dilihat bahwa produksi beras menjadi terus-menerus berkurang dalam perbandingan penduduk yang mengakibatkan naiknya harga beras. Kehidupan kaum buruh dan tani yang menggerakkan produksi tebu dan pabrik gula itu, kian lama kian buruk. Sebuah komisi Belanda sendiri di tahun 1900 telah melaporkan bahwa kehidupan rakyat Jawa dari hari ke hari semakin sengsara (Gie, 1999: 8).

Kesengsaraan di Hindia Belanda mengundang reaksi kuat terhadap kaum pribumi berhaluan kiri untuk melawan kolonialis dengan cara mendirikan media surat kabar, bacaan-bacaan sastra, dan rapat organisasi. Dalam tulisan Soetjipto di majalah Hidoep, 1 Maret 1925;

Kaum kapital tertawa-tawa,

Sehari-hari membikin pesta,

Sebab musuhnya telah hilang,

Rose Luxemburg dan Karl

Liebnecht melayang.

Kedua-duanya membela rakyat

Rakyat mana yang ditindas haibat,

Oleh si tamak, si jajilaknat,

Yang menghisap sampai melarat.

Semakin nyata kalau karya sastra adalah kegelisahan penulis. Pengarang memanfaatkan media novel, cerita pendek, dan puisi untuk memaparkan kejadian-kejadian kepada rakyat Hindia Belanda. Dibangunnya peristiwa yang diperankan para tokohtokohnya sekedar menghidupkan situasi teks agar mudah dipahami oleh pembaca saat itu. Ada kemungkinan besar kalau karya sastraini dibuat pengarang atas dasar memperkenalkan ideologi marxisme kepada masyarakat luas agar rakyat semakin sadar kondisi yang dialami dan bersedia untuk melakukan protes. 


\section{ANTARA BACAAN LIAR DAN BALAI PUSTAKA}

Pembicaraan karesteristik antara bacaan liar dan Balai Pustaka diibaratkan seperti minyak dan air.Keduanya sebagai media bacaan yang secara tekstual sangat bertentangan; antara pro dengan pemerintah Belanda dan melawan pemerintah Hindia Belanda.Dimensi formasi ideologi bacaan liar berangkat dari kegelisahan kondisi dan situasi sosial kaum pergerakan melalui beberapa penyesuaian tingkat pemahaman kelompok pendukungnya.Sedangkah garis kebijakan Balai Pustaka berkeinginan mempertahankan status kekuasaan imperialisme dan melindungi rakyat dari bacaan-bacaan yang dianggap mengancam pemerintah untuk bersikap kritis.

Dalam sebuah artikel di surat kabar Api, 25 Juli 1925 Moeso secara terus terang menentang produk Balai Pustaka, dia menyatakan bahwa "sekarang kewadjiban sekalian saudara jaitoe melawan pengaroeh Balai Poestaka. Sekarang kita haroes menerbitkan boekoe jang perloe, dan boekoe-boekoe tjerita sendiri, soepaja Ra'jat tidak terlepas dari pergerakan kita." Selain itu, di tahun sebelumnya Semaoen di majalah Keras Hati, Februari 1920 pernah memprotes produk bacaan kaum kapitalis, dan rakyat miskin dianjurkan untuk membaca sesuai kelasnya, dikatakan "kaoem kapital sekarang menerbitkan matjam-matjam boekoe jang tidak terhingga banjaknja. Itoe semoea maksoednja tidak lain jaitoe oektoek menjesatkan dan membingoengkan kaoem boeroeh, soepaja ia tidak bias melawan keras-kerasan sebagaimana mestinja."

Bacaan liar pada satu pihak, merupakan cerminan pemberontakan anti kolonialisme dan punya harapan keluar dari kolonialisme menuju Negara
merdeka.Selain melukiskan situasi pergerakan, serta eksploitasi kolonial, bacaan liar turut mendorong pembacanya untuk berpartisipasi dan bergerak bersama pergerakan untuk menentang kediktatoran kolonial.Dalam bacaan juga digambarkan perbedaanperbedaan derajat kolonial yang dihasilkan oleh kediktatoran kolonial. Kondisi rakyat jajahan ini jelas bertolak belakang dengan pengetahuan Eropa yang mengajarkan demokrasi dan menuntut ditinggalkannya perbedaanperbedaan derajat yang telah berakar dalam tata susunan kolonial. ${ }^{19}$

Balai Pustaka sebagai lembaga penerbitan tidak lepas dari sejarah berdirinya di akhir abad ke-19.Pada saat itu pemerintah Belanda banyak membuka sekolah untuk Bumiputera dengan maksud; (a) mendidik pegawaipegawai rendah yang dibutuhkan oleh pemerintah, dan (b) agar politik pengajaran tetap dikuasai oleh pemerintah.Akan tetapi, ternyata sekolah-sekolah tersebut makin luas sehingga banyak bangsa kita yang pandai membaca dan menulis.Pemerintah khawatir terhadap kegemaran membaca di kalangan rakyat. Untuk memenuhi hasrat membaca itu dengan keputusan no. 12 tanggal 14 September 1908 oleh pemerintah dibentuklah suatu komisi yang diberi nama Commissie voor de Inlandsche School en Volkslectuur (komisi untuk bacaan rakyat di sekolahsekolah Bumiputera) di bawah pimpinan G.A.J. Hazeu. Komisi ini makin lama makin luas dan makin bertambah kegiatannya, sehingga pada tahun 1917 diubah menjadi suatu badan penerbitan, dipimpin berturut-turut oleh D.A. Rinkes, G.W.J. Drewes, dan K.A.H. Hidding. ${ }^{20}$

Hal ini bisa diketahui bahwa berdirinya Balai Pustaka untuk menyediakan konsumsi bacaan kepada 
rakyat sekolah pribumi yang isi bacaannya sehaluan dengan pandangan politik pemerintah Belanda. Menurut Sarwadi (2004: 25-26), berdirinya Balai Pustaka memiliki beberapa tujuan, antara lain:

a. Agar kehausan membaca di kalangan rakyat bisa dicukupi dengan buku-buku yang diterbitkan sendiri sehingga tidak akan membahayakan ketertiban dan keamanan negeri.

b. Dengan menerbitkan sendiri bukubuku bacaan itu, pemerintah bermaksud secara tidak langsung memasukkan unsur-unsur penjajahan melalui bacaan. Hal ini tampak pada banyaknya cerita kepahlawanan yang disaring ke dalam Bahasa Indonesia dan juga adanya karangan-karangan yang baik cerita maupun gambaran dapat memberikan kesan buruk terhadap bangsa Indonesia, dan memberikan kesan baik terhadap usaha-usaha pemerintah Belanda di Indonesia.

c. Seakan-akan sebagai balas jasa atau sekedar untuk memberi hati kepada rakyat dalam hubungannya dengan politik etis pemerintah pada masa itu.

Lewat penerbit inilah masyarakat dibawa ke pemikiranpemikiran yang sesuai dengan pandangan pemerintah kolonial. Sejumlah novel yang terbit sebelumnya harus disensor, baik dari segi bahasa maupun isinya. Lewat redaktur, karya yang hendak diterbitkan diedit sedemikian rupa sehingga bahasanya sesuai dengan bahasa yang distandarkan Balai Pustaka, yakni bahasa Melayu Tinggi, sedangkan isi karya tidak boleh menyinggung politik atau yang berbau takhayul. $^{21}$

Tidak hanya lewat penerbitan bacaan karya sastra, media surat kabar adalah bagian terpenting ajang penyebaran perlawanan dan pendidikan rakyat. Pada suatu ketika, Mas Marco
Kartodikromo mengajak perang suara antara bacaan yang pro pemerintah dan bacaan pendidikan untuk kepentingan rakyat pribumi rendahan. Marco berharap agar rakyat dan kaum pergerakan bersikap kritis terhadap penerbitan surat kabar yang memihak kapitalis atau kepada buruh, dan masyarakat bisa terbuka pikirannya.

Perjuangan Mas Marco didukung oleh Moeso dalam tulisan di surat kabar Proletar, 23 Juli 1925. Moeso menyarankan agar rakyat membaca buku-buku, pikiran, dan moral dari kelasnya sendiri (proletar). Kelas kapitalis mempunyai kepentingan dan maksud sendiri, sedangkan kelas buruh bertentangan dengan kelas kapital. Rakyat yang tertindas hanya diam, tidak bisa berbuat apa-apa yang keras, karena pikiran dan nasehat-nasehat yang diadakan dari pihak kapitalis. Kelas yang tertindas harus menerbitkan bukubuku yang perlu dalam pertandingan melawan kapital. Begitulah nanti agar bisa terbebas dari kolonialisme dan imperialisme, dan bisa memudahkan datangnya komunisme.

Pendapat Moeso jelas-jelas memberikan kesadaran kepada umum, tapi pihak pemerintah merasa khawatir dan terancam kalau rakyat semakin radikal. Dengan membanjirnya bacaanbacaan, maka pemerintah menerapkan undang-undang pers tahun 1906 dan pasal 161 bis dari Strafwetbook pada 10 Mei 1923. Bunyi pasal 161 bis disiarkan surat kabar Sinar Hindia, 14 Mei 1923:

Barang siapa yang bertujuan untuk merusak ketertiban umum dan mengacaukan kehidupan ekonomi masyarakat, atau mengetahui bahwa tindakannya itu akan merusak ketertiban umum dan akan mengacau kehidupan ekonomi masyarakat, juga menyebabkan banyak orang mengabaikan atau menolak bekerja pada dinas di mana mereka telah terikat bekerja, dihukum dengan hukuman penjara 
paling lama lima tahun atau hukuman denda paling tinggi sebanyak f. 1000,--

Sehingga kaum pergerakan banyak yang dipenjara lantaran aturan ini, seperti Semaoen, Mas Marco Kartodikromo, dan Soemantri. Kalau dihubungkan dengan pasal 161 bis, surat kabar dari pihak kapitalis atau pemerintah dan penerbit Balai Pustaka jelas-jelas bermaksud menyebarkan politik untuk menjinakkan rakyat Hindia Belanda dan mengontrol perkembangan masyarakatnya.

Dengan kata lain, secara stilistik karya-karya yang terbit di Balai Pustaka tidak memperlihatkan gaya individual dari tiap pengarang dan dari segi isi tidak ada karya yang bertindak kritis terhadap kedudukan dan kebijakan pemerintah kolonial. Di bawah kontrol yang ketat itulah lahir sejumlah karya seperti Sitti Nurbaja, Salah Pilih, Karena Mentua, dan sejumlah karya lainnya yang tidak mengusung ide-ide politik. Kalaupun ada karya yang melukiskan peranan pemerintah, maka karya itu tidak memberikan cap negatif kepada pemerintah. Kematian Samsul Bahri dalam Sitti Nurbaja, misalnya, dicitrakan sebagai kematian yang agung karena mati untuk melawan keangkaramurkaan Datuk Meringgih yang mata keranjang, licik, dan anarkis (pembangkang, provokator, pembuat onar). Samsul Bahri justru muncul sebagai sosok yang berada dalam barisan pemerintah kolonial dalam memerangi kejahatan. ${ }^{22}$

\section{SIMPULAN}

Politik etis yang diperlakukan pemerintah Belanda berakibat pada rakyat berakhir kesusahan dan kemelaratan. Pemerintah bertambah rakus melakukan monopoli perdagangan terhadap barang dagangan yang pemerintah perlukan dan penyewaan lahan-lahan garapan rakyat secara paksa untuk ditanami tebu,akibat dari politik etis ini berdampak pada kemanusiaan maupun keuntungan ekonomi pemerintah.

Hal demikian, membawa rakyat berbondong-bondong pergi ke kota untuk menjadi buruh. Para pemodal yang mempunyai pabrik dan lahan bisnis memperkerjakan buruh dengan upah yang minim karena banyaknya tenaga manusia yang memerlukan pekerjaan, berdampak tingkat kesejahteraan buruh terabaikan. Jam kerja yang tidak seimbang dengan uang yang diterima dan tersedianya tempattempat hiburan yang bersifat mempengaruhi rakyat untuk bersikap boros disediakan oleh para pemodal.

Bersumber dari sistem pemerintah yang semakin terpuruk, rakyat yang sadar untuk perbaikan syarat-syarat ekonomi, sosial, dan politik, para buruh menyatukan diri dalam wadah organisasi berupa serikatserikat buruh. Selain dalam bentuk aksi nyata (pemogokan), kalangan gerakan buruh tahun 1920-an juga menyebarkan propaganda pandangan Marxis menggunakan media dan strategi yang bermacam-macam, ada yang menggunakan surat kabar, nyanyian, syair, novel, cerpen, dan vergadering. Novel Rasa Merdika adalah salah satu contoh, di mana pada saat itu pemakaian bahasa yang rendah (bahasa pasar atau bahasa sehari-hari masyarakat), diharapkan rakyat yang tidak mendapatkan pendidikan kurang sempurna mampu untuk memahami teks dalam novel.

Keberadaan karya sastra, khususnya novel pada saat itu dianggap berbahaya, mengancam keberadaan pemerintah dan para pemodal. Karyakarya atau bacaan yang dianggap liar ini menyuarakan kegelisahan penulis, memberikan bentuk protes kepada pemerintah, mengajarkan rakyat untuk 
menjadi pintar dan bersikap kritis terhadap peraturan yang berlaku sewenang-wenang. Para propagandis menawarkan ideologi komunis yang dianutnya, menyodorkan konsep ekonomi berbasis kerakyatan yang seharusnya di terapkan di tanah Hindia Belanda untuk menjadi negara yang mandiri terlepas dari kolonialisme.

\section{UCAPAN TERIMA KASIH}

Peneliti mengucapkan terima kasih kepada berbagai pihak yang telah membantu dalam proses penulisan artikel ini.

\section{PUSTAKA RUJUKAN}

Anderson, B. (1983). Imagined Communities: Reflections on the Origin and Spread of Nationalism. London: Verso.

Cahyono, E. (2003). Jaman Bergerak di Hindia Belanda: Mosaik Bacaan Kaoem Pergerakan Tempo Doeloe. Jakarta: Yayasan Pancur Siwah.

Damono, S.D.(2002). Sosiologi Sastra: Sebuah Pengantar Ringkas. Jakarta: Pusat Pembinaan dan Pengembangan Bahasa.

Gie, S.H. (1999). Di Bawah Lentera Merah. Yogyakarta: Yayasan Bentang Budaya.

Kartodikromo, M.M. (2002). Pergaulan Orang Buangan di Boven Digoel. Jakarta: Kepustakaan Populer Gramedia.

- (1919). Student Hidjo.

Semarang: N.V. Boekhandel en

Drunkkerij Masman \& Stoindk. Pringgodigdo, A.K.(1950). Sedjarah Pergerakan Rakyat Indonesia. Jakarta: Pustaka Rakyat.

Razif. (2005). Bacaan Liar Budaya dan

Politik pada Zaman

Pergerakan. Jakarta: Edi

Cahyono Experience.

Salim, I.F.M.C. (1977). Lima Belas Tahun di Digul: Kamp
Konsentrasi di Nieuw Guinea. Jakarta: Bulan Bintang.

Sarwadi. (2004). Sejarah Sastra Indonesia Modern. Yogyakarta: Gema Media.

Shiraishi, T. (2005). Zaman Bergerak: Radikalisme Rakyat di Jawa 1912-1926 (terj. Hilmar Farid). Jakarta: PT Pustaka Utama Grafiti. .(2001). Hantu Digoel: Politik Pengamanan Politik Zaman Kolonial. Yogyakarta: LKIS.

Soemantri. (1924). Rasa Mardika (Hikayat Soedjanmo). Semarang: Druk-kerij VSTP.

Sumarjo, Y. (1979). Masyarakat dan Sastra Indonesia. Yogyakarta: C.V. Nur Cahaya.

Kesusastraan Melayu Rendah Masa Awal. Yogyakarta: Galang Press.

Wasono,S.(2007). Rasa Merdika: Sebagai Propaganda Dan Perlawanan, makalah untuk Seminar Internasional Kesastraan yang diselenggarakan oleh Pusat Bahasa, Departemen Pendidikan Nasional, pada 19-20 November 2007 di Hotel Acacia, Jakarta.

Teeuw, A. (1980). Sastra Baru Indonesia. Ende-Flores: Nusa Indah.

Toer, P.A.(2003). Realisme Sosialis dan Sastra Indonesia. Jakarta: Lentera Dipantara.

Wasono, S. (2007). Sastra Propaganda. Jakarta: Wedatama Widya Sastra.

Yuliati, D.(2000). Semaoen: Pers Bumiputra dan Radikalisasi Sarekat Islam Semarang. Semarang: Bendera. 


\section{SURAT KABAR}

Sinar Djawa, 26 Maret 1918

Sinar Djawa, 1 April 1918

Sinar Djawa, 10 April 1918

Keras Hati, Februari 1920

Sinar Hindia, 17 Desember 1921

Sinar Hindia, 31 Mei 1923
Sinar Hindia, 14 Mei 1923

Sinar Hindia, 21 Juni 1923

Hidoep, 1 Maret 1925

Api, 25 Juli 1925

Proletar, 23 Juli 1925

\section{CATATAN:}

${ }^{1}$ Razif, Bacaan Liar Budaya dan Politik Zaman Pergerakan (Edi Cahyono's Experience, 2005), hlm.37-38. "Bacaan liar" merupakan label untuk tulisan-tulisan kaum pergerakan. Label ini pertamakali diberikan oleh Rinkes, direktur Balai Pustaka. Image "bacaan liar" yang diproduksi oleh kaum pergerakan ini diungkapkan Rinkes tahun 1914 dalam "De Imhemse Pers" karena kekhawatiran negara kolonial terhadap barang-mbarang cetakan seperti surat kabar, jurnal, novel, dan bentuk-bentuk bacaan lainnya. Rinkes menyatakan surat kabar harian maupun mingguan isinya sering kali provokatif-menyerang pemerintah kolonial, mengejek aturan-aturan pemerintah dan menyerang pejabat pemerintah maka bacaan-bacaan tersebut dianggap telah melanggar kekuasaan kolonial dan mengganggu ketertiban. Sebenarnya pernyataan Rinkes tersebut adalah hasil perdebatannya dengan Mas Marco pada tahun 1914 tentang hasil-hasil kerja Mindre Welvaart Commissie, yang dianggap Mas Marco sebagai usaha mempertahankan mitos politik etis

${ }^{2}$ Kaum kromo adalah sebutan untuk rakyat yang yang miskin dan tidak berpendidikan. Para pemimpin pergerakan dalam menghasilkan bacaan, baik berupa surat kabar, novel, roman, dan sebagainya menggunakan bahasa pasar atau bahasa Melayu rendah (bacaan populer). Ini dimaksudkan agar kaum kromo mempu memahami bangsanya yang sakit karena kemiskinan dan mengajak untuk melawan penjajahan. Dalam tulisan D.M.G Koch "Bating Slot: Figures uit het Oude Indie" (Razif, 2005: 26) menyatakan bahasa Melayu pasar adalah bahasa para pedagang dan kaum buruh yang tidak pernah mengenyam pendidikan sekolah dengan pengajaran bahasa Melayu yang baik.

${ }^{3}$ Edi Cahyono "Gelanggang Politik Gerakan Buruh di Hindia Belanda" sebuah pengantar dari kumpulan tulisan media masa kaum pergerakan dari tahun 1914-1925, yaitu "Jaman Bergerak di Hindia Belanda: Mosaik Bacaan Kaoem Pergerakan Tempo Doeloe" penerbit Yayasan Pancur Siwah tahun 2003.

${ }^{4}$ Dewi Yuliati, Semaoean Pers Bumiputera dan Radikalisasi Sarekat Islam Semarang( Bendera, 2000), hal. 2-3

${ }^{5}$ Edi Cahyono, Gerakan Serikat Buruh Jaman Kolonial Hindia Belanda Hingga Orde Baru (Hasta Mitra, 2003), hal. 116-117. Vereniging Spoor-Traam Personen (VSTP) didirikan pada 14 November 1908 di Semarang sebuah organisari gerakan buruh kereta api dan traam. Awal berdiri berjumlah 63 buruh impor Eropa yang bekerja pada 3 jalur kereta Nederlansch-Indische Spoorweg Maatschappij (NIS), Semarang-Joana Maatschappij Stoomtram (SJS) dan SemarangCheribon Stoomtram Maatschappij (SCS). Pada tahun 1913 anggota VSTP menjadi 1.242 (673 Eropa 569 Bumiputera) dan pada tahun 1915 berjumlah 2.292 anggota. Surat kabar yang didirikan, yaitu Si Tetap, Mohammad Joesoep sebagai editor pertama.

${ }^{6}$ D.A. Rinkes datang ke Hindia Belanda tahun 1910, seorang penasihat urusan Bumiputera, pegawai bahasa, dan direktur Balai Pustaka.

${ }^{7}$ Razif, Bacaan Liar: Budaya dan Politik pada Zaman Pergerakan (Edi Cahyono,s Experience, 2005), hal. 38.

${ }^{8}$ Ibid., hal. 1-2

${ }^{9}$ Novel Student Hidjo awalnya dimuat di surat kabar Sinar Hindia sebagai cerita bersambung, kemudian pada tahun 26 Maret 1919 diterbitkan N.V. Boekhandel en Drukkerij Masman \& Stroink Semarang. Novel ini ditulis Mas Marco di penjara akibat persdelict, di Civiel en Militair Gevangenhuis di Weltevreden, selama satu tahun. 
${ }^{10}$ I.F.M. Chalid Salim, Lima Belas Tahun di Digul: Kamp Konsentrasi di Nieuw Guinea (Bulan Bintang, 1977), hal.31.

${ }^{11}$ Karya Mas Marco lainnya adalah Babad Tanah Djawa, sebagai cerita bersambung di jurnal Hidoep tahun 1924-1925.

${ }^{12}$ Someoen kembali ke Indonesia lagi pada tahun 1953, dan tidak menganut pemikiran kiri. Ini bisa dibuktikan melalui pengamatan Edi Cahyono, bahwa Semaoen telah bergabung dengan Partai Murba dan menulis buku "Tenaga Manusia: Postulat Teori Ekonomi Terpimpin" terbit di Jakarta P.T. Penerbit Universitas

${ }^{13}$ Pada bulan berikutnya ada pemberitaan surat kabar Sinar Hindia, 21 Juni 1923 bahwa Samsi (redaktur harian Sinar Hindia) menulis "seharoesnjalah pemerintah dengan selekasnja memeriksa korban 161 bis itoe, soepaja nama dan keadilan pemerintah tidak tertjemar, lantaran menahan orang terlaloe lama jang beloem tentoe salahnja, karena salah faham"

${ }^{14}$ Mas Marco Kartodikromo, Pergaulan Orang Buangan di Boven Digoel (Kepustakaan Populer Gramedia, 2002), penyunting Koesalah Soebagyo Toer, hal. 67.

${ }^{15}$ Lihat Razif, Bacaan Liar: Budaya dan Politik pada Zaman Pergerakan (Edi Cahyono,s Experience, 2005), hal. 27 dan Pramoedya Ananta Toer, Sang Pemula, Jakarta: Hasta Mitra, 1985.

${ }^{16}$ Pernyataan ini disampaikan Soekindar, "Socialistische litteratuur di Hindia," Sinar Hindia, 17 Desember 1921.

${ }^{17}$ Razif, Bacaan Liar: Budaya dan Politik pada Zaman Pergerakan (Edi Cahyono,s Experience, 2005), hal. 102-103.

${ }^{18}$ Ibid., hal. 104-105.

${ }^{19}$ Lihat Razif, Bacaan Liar: Budaya dan Politik pada Zaman Pergerakan (Edi Cahyono,s Experience, 2005), hal. 107

${ }^{20}$ Sarwadi, Sejarah Sastra Indonesia Modern (Gema Media, 2004), hal. 24.

${ }^{21}$ Sunu Wasono, Rasa Merdika: Sebagai Propaganda Dan Perlawanan, makalah untuk Seminar Internasional Kesastraan yang diselenggarakan oleh Pusat Bahasa, Departemen Pendidikan Nasional, pada 19-20 November 2007 di Hotel Acacia, Jakarta, hal. 4.

${ }^{22}$ Ibid., hal. 4 